\title{
Pengaruh Sistem Pengendalian Internal, Budaya Organisasi, Komitmen Organisasi, dan Penegakan Hukum terhadap Kecendrungan Kecurangan di Lembaga Perkreditan Desa, (Studi Kasus pada Kecamatan Sawan Kabupaten Buleleng)
}

\author{
Kadek Hartani Graha Dewi ${ }^{1 *}$, Putu Eka Dianita Marvilianti Dewi ${ }^{2}$ iD \\ ${ }^{12}$ Porgaram Studi S1 Akuntansi, Fakultas Ekonomi, Unversitas Pendidikan Ganesha, Singaraja,lIndonesia \\ *hartanigraha23@gmail.com
}

\begin{abstract}
Abstrak
Tujuan dari penelitian ini adalah untuk mengetahui pengaruh sistem pengendalian internal, budaya organisasi, komitmen organisasi, dan penegakan hukum terhadap kecenderungan kecurangan pada LPD di Kecamatan Sawan. Penelitian ini menerapkan metode penelitian kuantitatif, dengan mengolah data primer. Teknik sampling untuk menentukan sumber data adalah metode purposive sampling, dan melibatkanLPD di Kecamatan Sawan. Sumber data dalam penelitian inidiperoleh dengan menggunakan kuisioner, dan kemudian diolah dengan uji analisis linear berganda di SPSS. Hasil penelitian ini menunjukan bahwa penerapan sistem pengendalian internal dan penegakan hukum secara parsial berpengaruh signifikan terhadap kecenderungan kecurangan pada LPD di Kecamatan Sawan. Sedangkan budaya organisasi, dan komitmen organisasi secara parsial tidak berpengaruhsignifikanterhadap kecenderungan kecurangan pada LPD di Kecamatan Sawan.
\end{abstract}

Kata Kunci : Sistem pengendalian internal, Budaya organisasi, Komitmen organisasi, Penegakan hukum, Kecenderungan kecurangan

\section{Abstract}

This purposes of research is to know the effect of the internal control system, organizational culture, organizational commitment, and law enforcement on fraud tendency of LPD in Sawan District. This research apply quantitative research methods, by processing primary data. Sampling technique for determine of data source is purposive sampling method, and that involves LPD in Sawan District. Data source of this research was obtained by using a questionnaire, and then it is processed by using multiple linear analysis test in SPSS. The results of research is show that implementation of internal control system and law enforcement partially has a significant effect on fraud tendency of LPD in Sawan District. While, organizational culture and organizational commitment partially have no significant effect on fraud tendency of LPD in Sawan District

Keywords: internal control system, organizational culture, organizational commitment, law enforcement, fraud tendency

\section{Pendahuluan}

Kecurangan termasuk penipuan secara nyata yang disengaja untuk mendapatkan data yang tidak sesuai dengan kebenerannya dan juga untuk memperoleh keuntungan finansial yang melanggar hukum. Praktik kecurangan atau dugaan misrepresentasi terjadi pada suatu lembaga keuangan baik berkaitan dengan sektor swasta maupun pemerintah oleh pihakpihak tertentu. Dalam Report to the National on Occupation Fraud and Abuse yang dikerjakan oleh Association of Certified Fraud Examiners (ACFE) pada tahun 2016, terungkap bahwa sebanyak $78,9 \%$ kasus pemerasan yang meliputi korupsi, penyalahgunaan

History:
Received: August 2021
Revised: Oktober 2021
Accepted: November 2021
Published: November 2021


sumber daya, dan ringkasan fiskal palsu, keduanya terjadi di sektor swasta dan pemerintahan di Indonesia (Christofel, 2010).

Institusi yang paling berpeluang menjadi sasaran kecurangan (fraud) adalah institusi yang berkecimpung di bidang finansial atau di lembaga perbankan, administrasi publik dan pemerintahan. Salahsatu organisasi9keuangan yang berdiri di wilayah desa, khususnya10di daerah Bali11adalah organisasi keuangan8yang disebut LembagaPerkreditannDesa12(LPD). Peraturan7Daerah6ProvinsiBali Nomor 3 Tahun 2017, Lembaga Perkreditan10Desa termasuk organisasi desa pakraman yang melakukan kegiatan di bidang yang berkaitan dengan keuangan desa pakraman untuk mengatasi masalah keuangan masyarakat di desal pakramanl. Peraturan45Daerah45Provinsi Bali Nomor 3oTahun02017 juga menjelaskan bahwa LPD1memberikan keuntungan finansial, sosial, dan budaya bagi rakyat desa pakraman.

Dari informasi yang disampaikan dalam rapat koordinasi pada 12 November 2010 menjelaskan bahwa LPD antara Komisi II DPRD Bali, Pemerintah Daerah Provinsi Bali, Bank Pembangunan Daerah Bali, Majelis Utama Desa Pakraman dan pihak-pihak akademi di Denpasar, terdapat 173 LPD dari total 1.405 LPD di Bali yang gagal menjalani kegiatan operasionalnya. Walaupun jumlah LPD yang gagal sangat besar, hingga mencapai lebih dari $12 \%$ dari jumlah seluruh LPD, akibat dari kurang dilakukan pengawasan dan pemeliharaan (Atmadja, dkk, 2015).

Lembaga Perkreditan Desa di Kabupaten Buleleng berjumlah sebanyak 169, hanya 63\% LPD yang dinyatakan sehat, yaitu sebanyak 106 LPD, tergolong cukup sehat sebanyak 24 LPD, yang tergolong kurang sehat 12 LPD, dan 4 LPD dinyatakan tidak sehat, serta LPD yang mengalami kemacetan sebanyak 23 LPD. Di Kabupaten Buleleng. Dengan adanya kasus LPD "tidak sehat" terus menerus terjadi di Kabupaten Buleleng, seperti.kasus penyelewengan dana LPD Gerokgak yang dilakukan oleh Ketua LPD sebesar Rp.1,2 Miliar dengan jangka waktu yang panjang belum tuntas ditangani (radarbali.jawapos.com, 2019).

Seperti yang ditunjukkan oleh Badan Pemeriksa Keuangan (BPK) RI (2007) kecurangan (fraud) dijelaskan sebagai suatu bentuk perbuatan melanggar hukum yang dilakukandengansengaja untuk mendapatkan sesuatu dengan menipu. Arens (2008:432) menjelaskan bahwa faktor dari tindakan kecenderungan kecurangan dikenal dengan istilah fraud triangle atau segitiga kecurangan, yaitu menjadi tekanan atau insentif (preasure), kesempatan (opportunity), dan sikap atau rasionalisasi (razionaltation).

Dari faktor-faktor yang menyebabkan kesalahan penyajian, peluang/kesempatan kecurangan merupakan salah satu faktor yang memungkin dengan baik untuk dikurangi dengan cara menerapkan controlling (pengendalian internal) yang meluas. Sebagaimana dijelaskan oleh Romney dan Paul(2015;226), pengendalian internal adalah interaksi yang dilakukan untuk memberikan penegasan yang memuaskan bahwa telah mencapai tujuan pengendalian. Berkenaan dengan penegakan hukum, termasuk melakukan tindakan terhadap penyimpangan atau pelanggaran dari pedoman yang sudah ditetapkan atau dikenal dengan tindakan melanggar hukum (Wulandari dan Ahmad, 2015).

Selain itu, faktor rasionalisasi dapat mencegah kecuranganyang merupakan gagasan yang melegitimasi perbuatannya sebagai tindakan yang semestinya, dan layak secara etis dalam masyarakat luas. Hal ini mengacu pada kultur atau budaya organisasi dan komitmen organisasi yang menjadi acuan pedoman perilaku dalam suatu lembaga. Luthans (2011: 13) mengartikan bahwa budaya organisasi adalah sikap kerangka berpikir yang dibimbing kepada individu baru organisasi sebagai cara pandang, perasaan dan tindakan secara efektif dan berurutan. Komitmen organisasi adalah seberapa besar keyakinan para pegawai menerima tujuan-tujuan organisasi yang ditetapkan, dan memiliki keinginan teguh untuk menetap bersama organisasi (Widiana dan Rusmawati, 2015). 
Dari peneliitian Rizky dan Fitri (2017) menunjukkan bahwa kecukupan pengendalian internal dalam mempengaruhi kecurangan, maka artinya semakin baik pengendalian internal, semakinrendah kecurangan pembukuan/akuntansi yang akan terjadi. Sementara itu, riset yang dikaji oleh Kusumastuti (2012) menyatakan bahwa kefektifan pengendalian internal tidak berdampak secara signifikan pada kecerungan akuntansi.

$\mathrm{H}_{1}$ :Sistem Pengendalian Internal berpengaruh signifikan terhadap Kecendrungan Kecurangan di LPD

Riset yang dikaji oleh Artini dan kawan-kawan (2014) menunjukkan bahwa fakta menegaskan bahwa ada dampak negatif dan signifikan antara budaya etis organisasi pada kecenderungan kecurangan akuntansi di Satuan Kerja Perangkat Daerah (SKPD) Kabupaten Jembrana. Sedangkan, penelitian yang ditunjukkan oleh Chandra (2015) menyatakan bahwa tidak ada pengaruh negatif antara budaya etis terhadap kecenderungan kecurangan akuntansi di sektor publik.

$\mathrm{H}_{2}$ : Budaya berpengaruh signifikan terhadap Kecendrungan Kecurangan di LPD

Menurut Tripermata (2016) menyatakan bahwa adanya hubungan yang negatif dan signifikan yang berpengaruh pada perbedaan kecenderungan kecurangan akuntansi antara seorang yang mempunyai tingkat komitmen/ tanggung jawab rendah dan tingkat komitmen yang besar. Sementara itu, Purwanti (2016) menyatakan bahwa komitmen organisasi pada individu tidak memiliki dampak signifikan terhadap kecenderungan kecurangan akuntansi.

$\mathrm{H}_{3}$ : Komitmen Organisasi berpengaruh signifikan terhadap Kecendrungan Kecurangan di LPD

Menurut Oktaviani (2017) bahwa kecenderungan kecurangan (fraud) dalam pengelolaan keuangan dipengaruhi oleh penegakan hukum secara positif dan signifikan yang diakibatkkan dari sebagian besar masyarakat memahami aturan tetapi tidak mematuhi aturan. Sedangkan, Purwati (2016) menyatakan bahwa tidak adanya pengaruh antara komitmen organisasi pada kecenderungan kecurangan (fraud) akuntansi. Dari premis hipotetis dan hasil dari penelitian yang terlebih dahulu, hipotesis penelitian yang diusulkan adalah:

$\mathrm{H}_{4}$ : Penegakan Hukum berpengaruh signifikan terhadap Kecendrungan Kecurangan di LPD

\section{Metode}

Penelitian ini mempunyai populasi sebanyak 18 LPD Se-Kecamatan Sawan Kabupaten Buleleng. Teknik peneltian ini yang digunakan untuk menentukan sampel, yaitu nonprobability sampling, dengan cara purposive sampling yang merupakan metode menentukan sampel yang disesuaikan dengan prasyarat sampel yang diperlukan. Sampel yang ditentukan adalah pegawai bagian internal LPD yang mengetahui dengan jelas berkaitan dengan kecenderungan kecurangan yang biasa terjadi di bagian keuangan. Dengan kriteria sampel yang dipilih yaitu Kepala LPD, Badan Pengawas LPD, dan 3 pegawai yang berkaitan dengan bagian keuangan atau akuntansi.

Riset ini menggunakan metode pengumpulan data yaitu, dengan cara menyebarluaskan kuesioner pada pihak yang bersangkutan. Kuesioner berisi tentang persepsi pegawai mengenai faktor-faktor yang mempengaruhi kecenderungan kecurangan (fraud). Kuesioner tersebut disebar langsung kepada pegawai yang bekerja pada LPD se-Kecamatan Sawan.

Sumber informasi utama dari riset ini adalah data-data yang telah ditetapkan sebagai sampel, kemudian data tersebut diolah menggunakan software SPSS (Statistical Product and Service Solutions) dengan model regresi.

\section{Hasil dan Pembahasan}




\section{Analisis Statistik Deskriptif}

Dalam riset ini, menguji dengan analisis0statistik deskriptif yang meliputi mean (ratarata), median (rata tengah), dan tabel frekuensi responden sesuai dengan klasifikasi yang penentuannya menggunakan0bantuan program SPSS (Statistical Product and Service Solutions), untuk menjabarkan dan mengkaji pengaruh variabel bebas (independen) dengan variabel terikat (dependen) dalam riset ini, maka akan dipresentasikan deskripsi data dari setiap variabel sesuai dengan data yang didapatkan dari lapangan.

Tabel 1. Hasil Statistik Deskriptif

\begin{tabular}{lccccc}
\hline \multicolumn{7}{c}{ Statistik Deskriptif } & & \\
\hline Variabel & N & Minimum & Maximum & Mean & Std. Deviation \\
\hline Sistem Pengendalian Internal & 81 & 46 & 60 & 51,21 & 3,907 \\
\hline Budaya Organisasi & 81 & 16 & 24 & 20,00 & 1,525 \\
\hline Komitmen Organisasi & 81 & 28 & 40 & 33,86 & 2,792 \\
\hline Penegakan Hukum & 81 & 18 & 25 & 21,49 & 1,804 \\
\hline Kecenderungan Kecurangan & 81 & 9 & 20 & 14,36 & 3,855 \\
\hline Valid N (listwise) & 81 & & & & \\
\hline
\end{tabular}

\section{Analisis Linier Berganda}

Pengaplikasian analisis linier berganda bertujuan untuk memutuskan seberapa jauh variable bebas independen $(\mathrm{X})$ mempengaruhi variabel dependen $(\mathrm{Y})$ dengan menggunakan aplikasi komputer IBM Statistical Package for Social Sience (SPSS) 21.0 For

Tabel 2 Hasil Uji Asumsi Klasik

\begin{tabular}{|c|c|c|}
\hline Uji Asumsi Klasik & Output/Hasil & Keterangan \\
\hline $\begin{array}{l}\text { Uji Normalitas } \\
\text { Asymp. Sig. (2-tailed) }\end{array}$ & 0,220 & Residual normal \\
\hline Uji Multikolinearitas & & \multirow{9}{*}{$\begin{array}{c}\text { Tidak terjadi multikolinearitas dari } \\
\text { variable-variabel penelitian, dilihat } \\
\text { dari nilai Tolerance yanglebih dari } 0,1 \\
\text { dan nilai VIF kurang dari } 10\end{array}$} \\
\hline Tolerance & & \\
\hline Sistem Pengendalian Internal & 0,364 & \\
\hline Budaya Organisasi & 0,813 & \\
\hline $\begin{array}{l}\text { Komitmen Organisasi } \\
\text { Penegakan Hukum } \\
\text { VIF }\end{array}$ & $\begin{array}{l}0,485 \\
0,485\end{array}$ & \\
\hline Sistem Pengendalian Internal & 2,748 & \\
\hline Budaya Organisasi & 1,230 & \\
\hline Komitmen Organisasi & 2,061 & \\
\hline Penegakan Hukum & 2,061 & \\
\hline Uji Heteroskedastisitas & 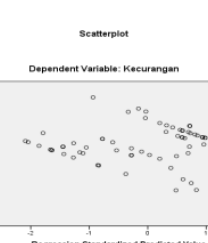 & $\begin{array}{l}\text { Grafik scatterplot atau titik-titik } \\
\text { terlihat tersebar di atas maupun di } \\
\text { bawah angka } 0 \text { pada sumbu Y dan } \\
\text { menyebar secara acak, maka artinya } \\
\text { data telah tersalur dengan normal atau } \\
\text { tidak terjadi heteroskedastisitas }\end{array}$ \\
\hline
\end{tabular}

Window. 
Koefisien determinasi, umumnya untuk menjadi tolak ukur sejauh mana potensi model Tabel 3. Hasil Analisis Regresi Linear Berganda

\begin{tabular}{lccc}
\hline Model & Unstandardized Coefficients & & \\
\hline (Constant) & B & t & Sig. \\
Sistem Pengendalian Internal & 49,295 & 9,708 & 0,000 \\
Budaya Organisasi & $-0,484$ & $-3,714$ & 0,000 \\
Komitmen Organisasi & 0,287 & 1,287 & 0,202 \\
Penegakan Hukum & $-0,133$ & $-0,840$ & 0,404 \\
\hline
\end{tabular}

dalam menjabarkan variasi variabel dependen (terikat). Nilai Adjusted $R$-Square menunjukkan seberapa besar nilai koefisien determinasi yaitu, 0,493 atau 49,30\%. Hal ini menunjukkan bahwa variabel sistem pengendalian internal $\left(\mathrm{X}_{1}\right)$, regresi budaya organisasi $\left(\mathrm{X}_{2}\right)$, komitmen organisasi $\left(\mathrm{X}_{3}\right)$, dan penegakan hukum $\left(\mathrm{X}_{4}\right)$ secara bersama-sama mempengaruhi kecenderungan kecurangan (Y) sebesar 49,30\% dan sisanya sebesar 50,70\% dipengaruhi oleh variabel lain yang tidak diteliti dalam penelitian ini. Nilai yang ditunjukkan dari hasil uji regresi berganda pada tabel diatas adalah

Koefisien Regresi Sistem Pengendalian Internal $(\beta 1)$ sebesar -0,484 menunjukkan bahwa setiap kenaikan variabel0X1 satu99satuan dengan asumsi bahwa variabel independen lainnya tetap/konstan, artinya terjadi penurunan pada variable kecenderungan kecurangan (fraud) sebesar -0,484. Budaya Organisasi (X2) mendapatkan nilai koefisien regresi sebesar 0,287 yang menjabarkan, yaitu satu satuan peningkatan setiap variabel X2 dengan asumsi bahwa variabel bebas lainnya tetap/konstan, maka akan ada penambahan kecenderungan kecurangan sebesar 0,287. Nilai Koefisien Regresi Komitmen Organisasi (X3) sebesar -0,133 menunjukkan bahwa setiap kenaikan variabel X3 satu satuan dengan asumsi bahwa variabel independen lainnya konstan, maka akan ada penurunan kecenderungan kecurangan sebesar 0,133. Nilai Koefisien Regresi Penegakan Hukum (X4) sebesar -0,532 menunjukkan bahwa setiap kenaikan variabel X4 satuesatuan denganUasumsi bahwa variabel independen lainnyaUkonstan kecenderungan kecurangan akan mengalami penurunan sebesar-0,532 .

\section{Pengaruh Sistem Pengendalian Internal (X1) terhadap Kecenderungan Kecurangan ( $Y$ )}

Hal yang diperoleh dari uji parsial (ujiaot) menunjukkan bahwa nilaioprobabilitas sebesar 0,000 dari variabel Sistem Pengendalian Internal (X1) kurang dari tingkat signifikansi $(0,000<0,05)$, menunjukkan Ho00ditolak dan Ha diterima, yaitu variabel X1 mempunyai pengaruh negatif dan signifikan secara parsial terhadap Kecurangan (Y).

\section{Pengaruh Budaya Organisasi (X2) terhadap Kecenderungan Kecurangan (Y)}

Dari hasil uji parsial (uji t) menunjukkan bahwa variabel budaya organisasi memilikiYnilaiOprobabilitas yang lebih besar dari nilai pada tingkat signifikansi $(0,202$ $>0,05)$, maka HoK diterima dan HaDditolak sehingga variabel $\mathrm{X} 2$ tidak mempunyai pengaruh yangGsignifikan terhadap Kecurangan (Y) secara parsial.

\section{Pengaruh Komitmen Organisasi X3 terhadap Kecenderungan Kecurangan ( $Y)$}

Dari uji parsial (uji t) dalam model regresi linier berganda menghasilkan nilai probabilitas variabel Komitmen Organisasi (X3) yang diperoleh sebesar 0,404 lebih besar dari tingkat signifikansi $(\alpha)$ yang telah ditentukan $(0,404>0,05)$, menunjukkan Ho diterim dan Ha ditolak sehingga variabel X3 tidak memunyai pengaruh yang signifikan secara parsial antara terhadap Kecurangan (Y). 
Pengaruh parsial Penegakan Hukum (X4) terhadap Kecenderungan Kecurangan (Y)

Dari uji parsial (uji t) dalam model regresi linier berganda menghasilkan nilai probabilitas variabel Penegakan Hukum (X4) sebesar 0,033 kurang dari nilai tingkatZsignifikansi $(0,033<0,05)$, menunjukkan HoSditolak dan HaTditerima artinya antara variabel X4 berpengaruhZnegatif danFsignifikan terhadap Kecurangan (Y) secara parsial.

\section{Simpulan dan Saran}

Dari hasil penelitian ini dapat ditarik beberapa kesimpulan yang dapat menjawab permasalahan yang terdapat dipenelitian ini yaitu 1) Hasil uji yang didapatkan mendukung hipotesis yang pertama yaitu, sistem pengendalian internal berpengaruh negatif dan signifikan terhadap kecenderungan kecurangan (Ha diterima dan Ho ditolak). Sehingga semakin meningkatnya efektivitas pengendalian internal, maka semakin rendah tingkat terjadinya kecenderungan kecurangan, 2) Hasil uji t menunjukkan menolak hipotesis yang kedua yaitu, tingkat signifikansi lebih kecil dari nilai probabilitas $(0,05<0,202)$ menunjukkan bahwa Ha ditolak dan Ho diterima, sehingga budaya organisasi tidak berpengaruh yang signifikan terhadap kecenderungan kecurangan, 3) Nilai dari riset dengan menggunakan uji t menghasilkan nilai probabilitas dari variabel komitmen organisasi lebih besar dari nilai pada tingkat signifikansi $(0,404>0,05)$ sehingga Ha ditolak dan Ho diterima (hipotesis ketiga ditolak) berarti komitmen organisasi tidak berpengaruh yang signifika nterhadap kecenderungan kecurangan, 4) Hasil uji variabel pada penegakan hukum dan kecenderungan kecurangan menunjukkan bahwa mendukung hipotesis keempat (Ha diterima dan Ho ditolak) yaitu, penegakan hukum berpengaruh negatif dan signifikan terhadap kecenderungan kecurangan, hal ini menunjukkan bahwa semakin efektif opengendalianointernal, maka tingkat terjadinya kecurangan akuntansi akan berkurang.

Adapun saran yang dapat peneliti sampaikanyaitu : 1) Bagi LPD se-Kecamatan Sawan diharapkan untuk memperhatikan dan menerapkan implementasi sistem pengendalian internal dan penegakan hukum kepada setiap pegawai LPD, karena kedua faktor tersebut kemungkinan dapat memaksimalkan pencegahan terjadinya kecenderungan kecurangan di Lembaga Perkreditan Desa se-Kecematan Sawan; 2) Bagi pihak peneliti diharapkan untuk melakukan penelitian selanjutnya agar dapat menambahkan dipengaruhi oleh variabel bebas lainnya yang tidak diteliti dalam penelitian ini, yang memungkinkan dapat mempengaruhi pencegahan kecurangan yang terjadi di LPD. Peneliti selanjutnya juga harus memperhatikan faktor-faktor yang memungkinkan mempengaruhi kecurangan (fraud) sebagai variabel bebasnya, seperti tekanan, kesempatan, dan rasionalisasi. Adapun juga agar penelitian selanjutnya dapat meneliti subjek penelitian dengan cakupan yang luas atau tidak hanya terbatas pada LPD se-Kecamatan Sawan.

\section{Daftar Pustaka}

ACFE Indonesia. 2016. Survei Fraud Indonesia, Association of Certified fraud Examiners.

Artini, Ni Luh E. A., dkk. (2014). Pengaruh Budaya Etis Organisasi dan Efektivitas Pengendalian Internal Terhadap Kecenderungan Kecurangan Akuntansi pada Satuan Kerja Perangkat Daerah (SKPD) Kabupaten Jembrana. Jurnal Ilmiah Akuntansi, 2(1)

Chandra, Prapnalia Devia. 2015. Determinasi Terjadinya Kecenderungan Kecurangan Akuntansi (Fraud) Pada Dinas Pemerintah Kabupaten Grobogan. Skripsi. Universitas Negeri Semarang. 
Christofel, S., Rendy. 2010. Modrasi Pengendalian Internal pada Hubungan Keadilan Organisasional Terhadap Tingkat Kecurangan (Fraud). Semarang.

Kusumastuti, N. R. 2012. Analisis Faktor-faktor yang Berpengaruh Terhadap Kecenderungan Kecurangan Akuntansi dengan Perilaku tidak Etis Sebagao Variabel Intervening. Skripsi. Semarang: Universitas Diponegoro.

Luthans, Fred. (2006). Perilaku Organisasi. Yogyakarta: Andi Offset.

Mustofa, Ali. 2019. Rugikan Negara Rp 1,2M Lebih, Ketua LPD Gerokgak Resmi Jadi Tersangka.

Dalam

https://www.google.com/url?sa=t\&source=web\&rct=j\&url=https://radarbali.jawapos.co $\mathrm{m} / \mathrm{read} / 2019 / 12 / 09 / 169502 /$ rugikan-negara-rp-12-m-lebih-ketua-lpd-gerokgak-resmijaditersangka\&ved=2ahUKEwiymvTm1prxAhWIYisKHZWHBO4QFjAEegQIBxAC\&usg $=$ AOvVaw0uCVoropy_eD6-mxOiHi24\&cshid=1623796105830, diakses tanggal 30 Mei 2020

Oktaviani, I. A. A., dkk. 2017. Pengaruh Praktik Akuntabikitas, Conflict of Interest dan Penegakan Hukum Terhadap Potensi Fraud Dalam Pengelolaan Keuangan Desa di Kabupaten Buleleng. Jurnal Akuntansi Program S1, Vol. 8, No. 2.

Purwanti, Sri. 2016. Pengaruh Sitem Pengendalian Internal, Kesesuaian Kompensasi, Moralitas Manajemen, Penegakan Hukum / Peraturan, Komitmen Organisasi dan Asimetri Informasi Terhadap Kecenderungan Kecurangan Akuntansi (Fraud) (Studi Kasus Pada Dinas Kabupaten Kudus). Skripsi. Kudus: Universitas Muria Kudus.

Rizky, Muammar dan Fitri, Fauziah A. 2017. Pengaruh Keefektifan Pengendalian Internal, Ketaatanaturan Akuntansi, Penegakan Hukum, Dan Perilaku Tidak Etisterhadap Kecurangan Akuntansi. Jurnal Ilmiah Mahasiswa Ekonomi Akuntansi, Vol.2, No.2, pp: 10-20.

Wulandari, S. dan Zaky, Ahmad. 2015. Determinan Terjadinya Fraud di Intansi Pemerintah (Persepsi pada Pegawai BPK RI Perwakilan Provinsi NTB). Jurnal Publikasi.

Widiana, M. E. 2015. Variabel dan Indikator yang Mempengaruhi Komitmen dan Kinerja Organisasi Pemerintah. Jurnal Universitas Bhayangkara Surabaya 